\title{
On the Training Mode of New Engineering Specialty Based on TRIZ Theory
}

\author{
${ }^{*}$ Yaxin Zhang ${ }^{1,}$ Di Zhu ${ }^{2}$ \\ ${ }^{1}$ Department of College of Physical and Intelligent Manufacturing Engineering, University of Chifeng, Inner \\ Mongolia, China \\ ${ }^{2}$ Chifeng agricultural and animal husbandry mechanization research and promotion service center, Inner Mongolia, \\ China \\ *Corresponding author. Email: Zhangyaxin1981@126.com
}

\begin{abstract}
In order to actively respond to the new round of scientific and technological revolution and industrial change, China has put forward a series of national strategies such as supporting service innovation driven development and "made in China 2025". The implementation of these national strategies needs the support of education. Therefore, education should adjust the traditional training methods to adapt to the development of new engineering. It mainly refers to the specialty of emerging industries, with Internet and industrial intelligence as the core, including big data, cloud computing, artificial intelligence, blockchain, virtual reality, intelligent science and technology and other related engineering majors. In this paper, TRIZ theory is used as a tool to analyze the training program, curriculum system and teaching mode of new engineering, and puts forward the feasible training mode strategy.
\end{abstract}

Keywords: TRIZ theory, New engineering, Professional training

\section{INTRODUCTION}

The future emerging industries and new economy need high-quality compound talents with strong practical ability, strong innovation ability and international competitiveness. According to the needs of future talents, on March 15, 2018, the general office of the Ministry of Education issued the notice of the general office of the Ministry of education on announcing the first batch of "new engineering" research and practice projects (jghth [2018] No. 17). The Ministry of Education decided to identify 612 projects as the first batch of "new engineering" research and practice projects, and announced the "list of the first batch of" new engineering "research and practice projects". New engineering major mainly refers to the major of emerging industries, with Internet and industrial intelligence as the core, including big data, cloud computing, artificial intelligence, blockchain, virtual reality, intelligent science and technology and other related engineering majors.

The new engineering specialty is divided into three types: new engineering specialty, new engineering specialty and new engineering specialty. The new engineering specialty is aimed at the "stock" of traditional and existing engineering specialty, facing the needs of future industrial development, transforming, transforming and upgrading through the infiltration of informatization, intelligence or other disciplines, namely "updating". The "new" of new engineering specialty can be reflected in the reform, change and development of the main links in the whole process of personnel training. As the "incremental supplement" of new engineering, the setting of new engineering specialty and new engineering specialty is to advance the layout and cultivate talents leading the future development of technology and industry. Based on the accurate grasp of the future demand and development direction of the country and industry, it needs to be carefully made through scientific and meticulous feasibility analysis and demonstration[1-2].

TRIZ theory was founded in 1946 by the former Soviet Union scientist Archie Schuler. Its Chinese meaning is the theory of solving invention problems. By analyzing more than 2.5 million invention patent documents, summarizing and sorting out the law of innovation, and further refining the methods and tools, TRIZ theory is obtained. TRIZ theory is based on knowledge, which can be realized on the basis of mastering certain system knowledge: the application 
theme of TRIZ theory is people, not problems or systems; TRIZ theory is a system, and the process of problem analysis and solution is to use knowledge for systematic processing. Therefore, for some problems or system contradictions that may never be encountered, we can also analyze and solve them according to the specific process through the method and tool of TRIZ theory. TRIZ theory has a wide range of applications, not only in product development and technological innovation, but also in the field of management. TRIZ theory system has a large number of tools and methodology. Using TRIZ theory to analyze the training mode of new engineering major from a macro perspective can more systematically and intuitively analyze problems and formulate solutions[3-4]

\section{NEW ENGINEERING TRAINING PROGRAM FORMULATION}

\subsection{Traditional engineering training program}

Talent training program refers to the total process of talent education under the guidance of certain educational theory and educational ideology, according to specific training objectives and talent specifications, with relatively stable teaching content and curriculum system, management system and evaluation mode. At present, the main problem in the traditional professional training of Engineering in China is the contradiction between the requirements of social industry development and talent training. In the traditional professional training mode, the educational theory and thought have a serious lag. Traditional emphasis on professional knowledge and humanistic literacy has not been eradicated. Since then, the cultivation of highly professional talents in accordance with the traditional planned economy mode is relatively weak in terms of humanistic literacy, most of which appear in the form of elective courses, and the degree of attention is not enough. At the same time, there are many situations in the cultivation of practical ability, which are mainly through simple social practice or scientific research projects. In the project teaching, the project selection is not proper, the construction of project library is not perfect, and the importance of project teaching is not fully recognized. The problems in the process of teaching implementation are diversified[5].

\subsection{Design of new engineering training program}

Based on TRIZ theory, the new engineering training program is formulated. It mainly relies on the project to carry out research-oriented teaching, project laboratory, science and technology competition, school enterprise cooperation and other forms. Through a variety of teaching methods, a large number of compound senior engineering talents with strong comprehensive innovation ability are cultivated. According to the specific professional characteristics and business training requirements, talents should acquire the following knowledge and abilities: solid basic knowledge of natural science, systematic basic knowledge of technology, basic skills and knowledge application ability of the specialty, professional knowledge in the field of the specialty, scientific research and management ability, knowledge acquisition ability, comprehensive analysis ability Innovative thinking and practical ability. The specific training program design is as follows:

First of all, based on the project design to cultivate engineering ability. With project design as the guidance and engineering ability training as the goal, classroom teaching and practice teaching are integrated into the project. In the initial stage, guiding courses or lectures are carried out to make students interested in the course and have a preliminary understanding. In the future knowledge learning, they are connected with practical projects and focus on the process of learning professional knowledge, Better use of knowledge in the future project design to the implementation of a series of processes, making a virtuous circle between learning and application.

Secondly, the establishment and selection of the project should consider the interdisciplinary, comprehensive integration project is conducive to different grades and professional students to participate in the similarities and differences, in the project learning to obtain active learning methods and ability, better grasp the professional theoretical knowledge.

Thirdly, science and technology competition is an extracurricular activity worthy of promotion. In the process of competition, students from different majors, colleges and countries can communicate with each other, which can not only promote their creativity and practical ability, but also strengthen their awareness of interpersonal communication and team cooperation, which are indispensable abilities and qualities for higher engineering talents.

Finally, the innovative research training plan can be implemented for the training objects of new engineering major. Students can establish and apply for projects according to their own interests and expertise. The school can open the laboratory and experimental equipment, so that students can put their innovative ideas into practice, and at the same time, they can use the theoretical knowledge, which promotes the win-win of theoretical knowledge and practical ability. In addition, the school strengthens the establishment of student project practice base. The purpose of establishing the practice base is to transform students' ideas into social resources under possible conditions. Through the process of project conception, design, implementation and operation, teaching and scientific 
research activities are integrated into it, which not only promotes the improvement of practical ability, but also promotes the operation and implementation of the project, Further develop students' team spirit, communication ability, organizational ability and other comprehensive quality[6-7].

\section{CONSTRUCTION OF NEW ENGINEERING CURRICULUM SYSTEM}

According to incomplete statistics, in many universities in China, theoretical teaching accounts for more than $60 \%$, experimental teaching accounts for about $30 \%$, and innovation guidance accounts for less than one tenth of the curriculum. The engineering talents cultivated under this process system have narrow knowledge, weak independent innovation ability and learning ability, and obvious deficiencies in comprehensive quality and ability in specific engineering practice. Therefore, in order to train engineers who can complete the construction of the whole, it is necessary to cultivate "soft skills" with integrated knowledge structure and "whole person" with "high quality". Therefore, in the aspect of teaching mode, the new engineering curriculum must revise the narrow, separate and independent mode in the past, re plan and overall design, form an orderly integrated curriculum system, organically combine all kinds of knowledge, and cultivate high-quality compound new engineering talents with strong practical ability, strong innovation ability and international competitiveness [8].

According to the TRIZ theory analysis method, we should use restraint from the perspective of curriculum structure. In the initial stage of undergraduate curriculum, we should pay attention to the basic knowledge of corresponding majors and core engineering knowledge, and cultivate a sense of social responsibility and good professional ethics in the humanities; In the middle stage, on the basis of learning core professional courses, engineering projects will be introduced into specific professional learning. Guided by the concept of "learning by doing", based on the syllabus, and in the form of project team, students' awareness of autonomous learning and team cooperation will be improved, and their ability of project organization and management will be cultivated and strengthened, so that students can not only acquire basic professional knowledge, but also improve their ability of project management, And enrich and improve the comprehensive practical ability; In the course arrangement of the Fourth academic year, we should strengthen the cultivation of professional skills and enrich their professional practical experience. During this period, we should organize effective engineering practice training to find, analyze and solve problems in the process of practice, so as to carry out professional learning independently, expand their own skills and achieve the purpose of improving their comprehensive quality. It's better to teach fish than to teach fish. The real wealth is not how much knowledge is instilled in the school, but how to let students learn self-learning, self-improvement, acquire the ability to discover and analyze problems, and have innovative thinking and ability. This is the primary goal of new engineering training.

\section{THE IMPROVEMENT OF TEACHING MODE}

\subsection{Teaching system}

To integrate TRIZ theory into the training of new engineering majors, we need to have a deep and objective understanding of the law of talent training. The learning process needs to be gradual, teaching students in accordance with their aptitude when conditions permit, and teaching students differently according to their different learning degrees and hobbies, which is more conducive to students' absorption and application of knowledge, The construction of specific teaching system is as follows:

- The individualization of the training program. The individualization here is not a simple batch teaching, but a study of different experiments and different projects according to the students' levels and interests. In the form of study group or project group, under the guidance of teachers, they can choose experiments independently and carry out a series of work such as the conception, design and implementation of experiments. In this process, members of the group can not only consolidate their knowledge and improve their ability through independent experiments or projects, but also further cultivate their teamwork and organizational ability, And further understand the connotation and application of basic theory, increase the enthusiasm of learning in the future.

- The diversification of teaching forms is not limited to the classroom, through a variety of combinations inside and outside the classroom, inside and outside the campus, the practical activities will be more specific and in-depth integrated into the training system, enrich the teaching forms, and more importantly, choose the teaching forms according to the actual teaching needs.

- The development of sustainable practice teaching requires a large number of scientific research projects and engineering projects. Through the form of school enterprise cooperation, combination of production, teaching and research, and cooperation inside and outside the school, the projects are introduced to connect the teaching projects with the society and enterprises, so as to cultivate innovative higher engineering talents more effectively. 


\subsection{Teaching method}

Enriching teaching methods the teaching methods and educational means of colleges and universities in China are still limited by the traditional teaching methods and educational means. The teaching methods are single and mainly classroom teaching. In order to break the rigid traditional teaching mode of teachers' speaking and students' recording, which centers on teachers, classrooms, teaching materials and examinations, we can further enrich the teaching methods, Discussion, role play, case analysis and other teaching methods can not only improve students' interest in learning, but also provide students with more relaxed and independent thinking space, guide students to explore learning, and play a positive role in the cultivation of innovative thinking and innovative ability.

It is necessary to strengthen the students' subjectivity in classroom teaching. In many colleges and universities, teachers are still the center of classroom teaching. Students just passively wait for the transfer of knowledge, which seriously restricts the students' innovative thinking. It is very necessary to strengthen the students' subjectivity in classroom teaching, Let students think more about themselves, find problems, analyze problems and solve problems. In this process, it is not necessary to get what kind of answers, but the important thing is the process. Through this form, let students actively participate in classroom teaching, think actively and explore independently. As time goes by, they will become a habit, which will benefit students for life.

At the same time, with the full application of computers in various fields, the teaching methods in Colleges and universities have been optimized on this basis. The application of science and technology will further facilitate teachers' teaching. What we need to pay attention to here is the enrichment and innovation of teaching methods. We cannot ignore the update of content. In the process of cultivating innovative talents, we should pay attention to the enrichment and innovation of teaching methods, the development of science and technology provides more possibilities for educational means.

\section{CONCLUSION}

In this paper, the original methods and tools of analyzing the contradiction of physical system are applied to the analysis of the training mode of new engineering students. The abstract education mode is regarded as an abstract system. TRIZ theory is used to have a more intuitive and specific understanding and analysis of the training mode of new engineering students This paper puts forward some suggestions for reference from three aspects of curriculum system and teaching mode to further improve the training mode of new engineering.

\section{ACKNOWLEDGMENTS}

This work was supported by Eucation and teaching research project of Chifeng University in 2021 ( JYXMY202147), "Research on the innovative ability training mode of new engineering specialty based on TRIZ theory"

\section{REFERENCES}

[1] LindeH, HerrG, Rehklau A. Hidden Pattern of Innovation Innovation of Knowledge Enterprises by WOIS $[\mathrm{M}]$. Boston : Springer Boston, 2006:1037-1041

[2] ShenYingting, Smith S.Product Redesign Using TRIZ and Contradictive Information from the Taguchi Method[M]. London: Springer London, 2009: 487-497.

[3] $\mathrm{Bi}$ Zhongyi. Research on the problems and Countermeasures of innovative engineering science and technology personnel training in China [D]. Lanzhou: Lanzhou University, 2012, 10-37

[4] Wang Ping, Cheng Jinhua, Zhang Huilan. Exploration on teaching reform of "hydraulics" course for soil and water conservation specialty [J]. China forestry education, 2017 (6): 49-52.

[5] Chen Zhengquan. How to improve the effectiveness of post practice [J]. Jiangsu Science and technology information,2014(15):80-81.

[6] Xie Jianghuai. Problems and Reflections on teaching practice reform of mechanical electronics specialty under " $3+1$ " talent training mode [J]. Internal combustion engine and accessories, 2019 (08): 240-241.

[7] Lu Xiaohua. Understanding and training methods of engineering innovation ability [J. research on higher engineering education, 2013 (2): 14-18.

[8] Wu Xingfu, Xu Ning. Higher vocational curriculum and students' innovation ability training [J]. Heilongjiang Higher Education Research, 2011 (6): 41-43. 